\title{
NIOSH CENTER FOR MOTOR VEHICLE SAFETY STRATEGIC PLAN, 2020-2029
}




\section{DISCLAIMER}

Mention of any company or product does not constitute endorsement by the National Institute for Occupational Safety and Health, Centers for Disease Control and Prevention. In addition, citations to websites external to $\mathrm{NIOSH}$ do not constitute $\mathrm{NIOSH}$ endorsement of the sponsoring organizations or their programs or products. Furthermore, NIOSH is not responsible for the content of these websites. All web addresses referenced in this document were accessible as of the publication date.

\section{GET MORE INFORMATION}

Find NIOSH products and get answers to workplace safety and health questions:

1-800-CDC-INFO (1-800-232-4636) I TTY: 1-888-232-6348 $\mathrm{CDC} / \mathrm{NIOSH}$ INFO: cdc.gov/info I cdc.gov/niosh

Monthly NIOSH eNews: cdc.gov/niosh/eNews

\section{SUGGESTED CITATION}

NIOSH [2020]. NIOSH Center for Motor Vehicle Safety Strategic Plan, 2020-2029. By Pratt S, Retzer K, Rodríguez-Acosta R, Olsavsky R, Fosbroke D. Morgantown, WV: U.S. Department of Health and Human Services, Centers for Disease Control and Prevention, National Institute for Occupational Safety and Health. DHHS (NIOSH) Publication No. 2020-126.

DHHS (NIOSH) Publication No. 2020-126

https://doi.org/10.26616/NIOSHPUB2020126 • June 2020 


\section{TABLE OF CONTENTS}

NIOSH Center for Motor Vehicle Safety...........................4

Background......................................................................... 5

Developing the Plan .......................................................... 7

How the Plan Will Be Used................................................9

Strategies and Tactics ........................................................ 10

Communication Strategies .............................................. 17

Achieving Impact and Evaluating the Plan .................... 18

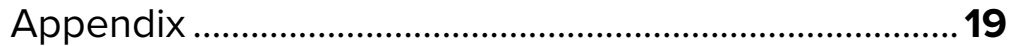




\section{NIOSH CENTER FOR \\ MOTOR VEHICLE SAFETY}

The National Institute for Occupational Safety and Health (NIOSH) Center for Motor Vehicle Safety (CMVS) includes a Lead Team, Steering Committee, researchers, communicators, and others across NIOSH locations. With our partners, we conduct research and develop strategies to prevent work-related motor vehicle crashes and resulting injuries.

The CMVS Lead Team, with input from the Steering Committee, coordinates research, communication, and policy activities in work-related motor vehicle safety by:

- Setting priorities for NIOSH motor vehicle safety research

- Helping NIOSH researchers develop strong research proposals to address these priorities

- Sharing knowledge with CMVS researchers and other NIOSH programs

- Developing public and private sector partnerships

- Contributing to NIOSH policy activities related to motor vehicle safety

- Communicating research results and crash-prevention recommendations to employers, workers, and others

The CMVS Lead Team prepared this strategic plan, with contributions from the CMVS Steering Committee and other NIOSH researchers.

\section{CMVS LEAD TEAM}

Dawn Castillo, MPH

Manager

Stephanie Pratt, PhD

Director (retired)

Kyla Retzer, MPH

Coordinator

Rosa Rodríguez-Acosta, PhD

Assistant Coordinator

David Fosbroke, MSF

Long Term Planning Coordinator

Rebecca Olsavsky, MS

Health Communication Specialist

\section{CMVS STEERING COMMITTEE}

Anasua Bhattacharya, PhD

David L. Caruso, MA

Jonathan E. Friedel, PhD

Emily J. Haas, PhD

Edward (Ted) Hitchcock, PhD

Hongwei Hsiao, PhD

Joan Karr, PhD

William (Karl) Sieber, PhD

Hope Tiesman, PhD 
Motor vehicle crashes are the leading cause of work-related deaths in the United States. ${ }^{1}$ Crashes affect workers in all industries and occupations, whether they drive heavy trucks, emergency vehicles, pickup trucks, or cars, and whether driving is a primary or occasional part of the job. To address this important worker safety issue, the National Institute for Occupational Safety and Health's (NIOSH) Center for Motor Vehicle Safety (CMVS) conducts research and develops strategies to prevent work-related motor vehicle crashes and resulting injuries. The CMVS uses a multidisciplinary approach to inform and conduct research, evaluate interventions, communicate prevention information, and foster partnerships to keep workers safe on the road.

$\mathrm{NIOSH}$ has conducted research on work-related motor vehicle safety for more than 20 years, but a formal structure to coordinate this work did not exist until 2010. At that time, NIOSH established the CMVS to strengthen and sustain its activities surrounding this safety topic. CMVS researchers across NIOSH work with partners to identify crash risk factors, develop and evaluate workplace interventions to prevent crashes and injuries, and share the results with employers, workers, and others.

The CMVS includes a Lead Team, a Steering Committee, and more than 40 team members, all located in NIOSH offices across the U.S. Team members' expertise includes epidemiology, statistics, engineering, human factors, psychology, policy science, economics, occupational safety and health, and communications.

$\mathrm{NIOSH}$ is the only part of the U.S. federal government whose mission includes prevention of work-related crashes and resulting injuries for workers who drive all types of vehicles (not just the commercial motor vehicles regulated by the U.S. Department of Transportation).

The work of the CMVS covers the prevention of work-related motor vehicle crashes and resulting injuries, which affect workers in all industries and occupations. Work-related crashes include:

- Single- or multiple-vehicle crashes, on or off public roadways, which occur on the job

- Events in which a pedestrian worker (e.g., a law enforcement officer) is struck by a motor vehicle in operation, on or off a public roadway

Although the CMVS follows the U.S. definition of a work-related crash, which excludes commuting-related crashes, CMVS research does consider commuting time and distance as potential risk factors for crashes and injuries.

From 2014 through 2018, the CMVS followed a 5-year strategic plan for research and prevention, pursuing 5 strategic goals: 1) identify risk factors for work-related crashes; 2) apply engineering and technology-based safety interventions; 3) promote evidence-based policies and practices; 4) share NIOSH research with global partners; and 5) communicate safety and policy recommendations.

In 2016, the CMVS conducted a midcourse review of the plan, which assessed progress on the 5 goals and confirmed that original priorities in the plan were still relevant. In 2018, the CMVS evaluated progress on the strategic goals for the full 5 years of the plan, sharing the findings through: 1) an evaluation report; 2) a report of progress on performance measures; and 3) 5 "impact stories" that serve as examples of actions, findings, outputs, and impacts for selected populations at elevated crash and injury risk.

${ }^{1}$ Bureau of Labor Statistics [2019]. Table A-2. Transportation incidents and homicides by detailed event or exposure, $2003-2018$. 
The midcourse review and 5-year evaluation are the foundation for this NIOSH Center for Motor Vehicle Safety Strategic Plan, 2020-2029. As described under "Developing the Plan," other sources also helped to guide the development of this new plan, including the NIOSH Strategic Plan: FYs 2019-2023, planning documents and research agendas from organizations whose work is relevant to work-related motor vehicle safety, and the experience and expertise of CMVS Lead Team and Steering Committee members. 


\section{DEVELOPING THE PLAN}

\section{NIOSH CENTER FOR MOTOR VEHICLE SAFETY STRATEGIC PLAN, 2020-2029}

This plan was developed with input from several sources:

- Subject matter expertise and knowledge of the research and policy environment, contributed by the CMVS Steering Committee and CMVS Lead Team

- NIOSH Strategic Plan: FYs 2019-2023

- A formal evaluation of progress on research and prevention goals in the NIOSH Center for Motor Vehicle Safety Strategic Plan for Research and Prevention, 2014-2018

- Review of activity/output goals from the 2014-2018 strategic plan to assess the need to carry over any goals into this strategic plan

- Review of research agendas and strategic plans from other organizations with interest in work-related motor vehicle safety

- Public comments obtained through a Federal Register Notice, with responses placed in a NIOSH docket

The CMVS Steering Committee and Lead Team agreed on strategies to guide CMVS research and prevention activities for 2020-2029. Using the inputs above, they then developed focused tactics: actions to support each of the strategies. 


\section{ROLE OF THE NIOSH STRATEGIC PLAN: FYs 2019-2023}

The NIOSH Strategic Plan: FYs 2019-2023 defined the scope of this NIOSH Center for Motor Vehicle Safety Strategic Plan, 2020-2029. The NIOSH strategic plan identifies motor vehicle safety research as a priority for these four industry sectors:

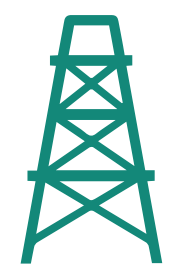

Oil and Gas Extraction

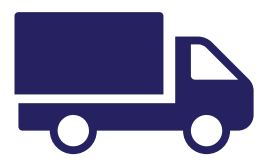
Transportation, Warehousing, and Utilities

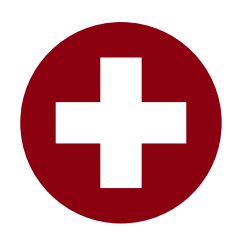

Public Safety

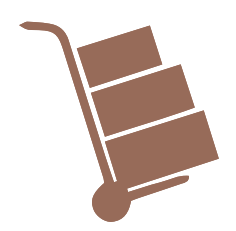

Wholesale and Retail Trade

Within these sectors, the NIOSH strategic plan identifies priority safety issues, worker populations, and types of research needed. For more information about the relationship between motor vehicle safety topics in the CMVS and NIOSH strategic plans, see the Appendix.

This CMVS strategic plan for 2020-2029 begins with priorities defined in the NIOSH Strategic Plan: FYs 2019-2023, but expands on the NIOSH strategic plan in two important ways. First, it provides more specific guidance on tactics needed to achieve the motor vehicle-related goals in the NIOSH strategic plan. Second, it goes beyond segmentation of research and communication needs by industry sector to specify strategies and activities that will benefit workers in all sectors, reflecting the crosscutting nature of work-related motor vehicle safety. 


\section{HOW THE PLAN WILL BE USED}

This CMVS strategic plan for 2020-2029 serves several purposes:

- To guide internal $\mathrm{NIOSH}$ researchers and program leaders in developing and encouraging development of research proposals that align with CMVS and NIOSH priorities

- To guide external researchers, including those who wish to apply for NIOSH funding, in developing research proposals that align with CMVS and NIOSH priorities

- To inform the research community and other federal agencies of CMVS and NIOSH research priorities, encouraging information exchange and collaborations
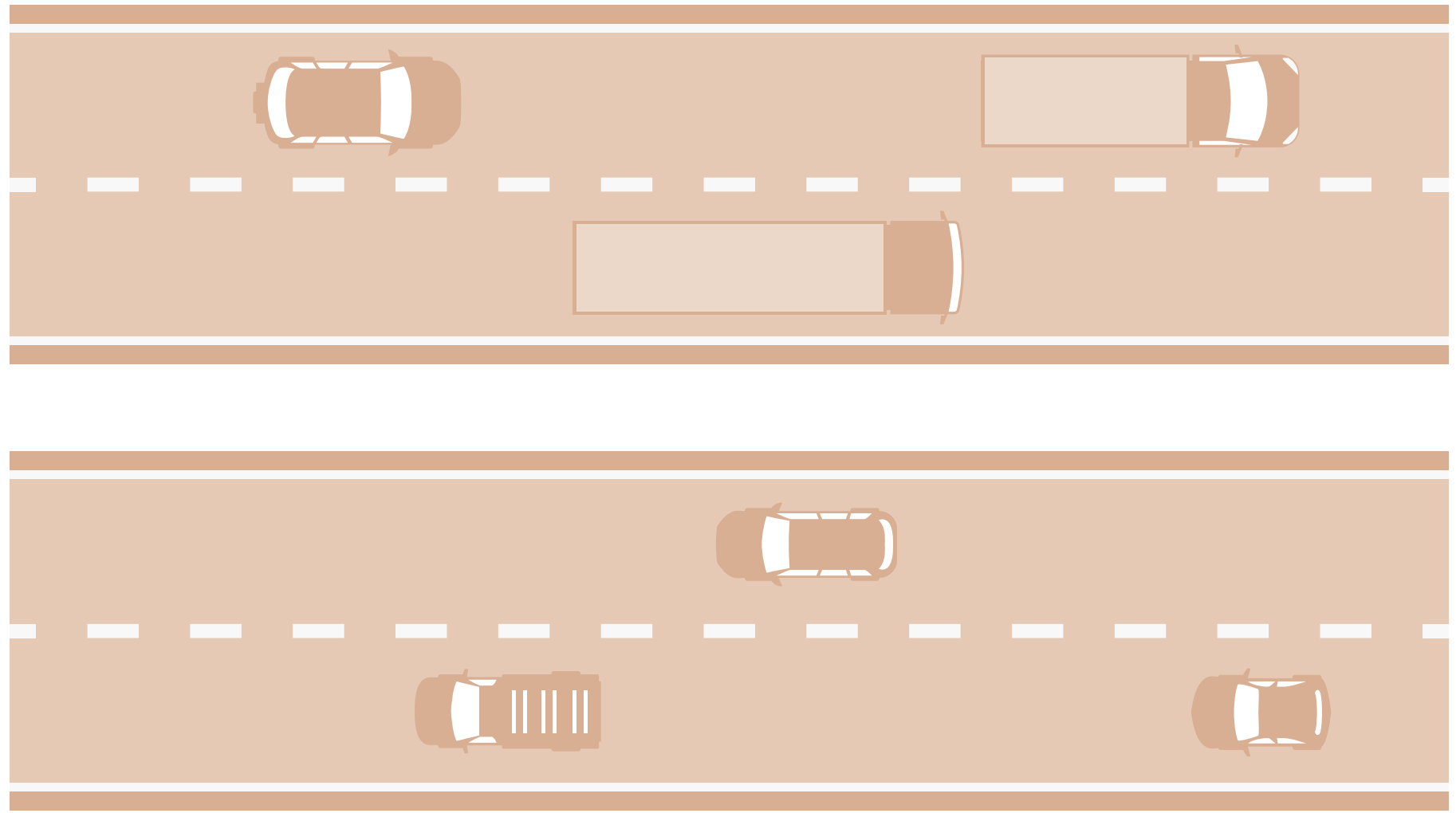


\section{Strengthen understanding of how risk factors contribute to work-related motor vehicle crashes and injuries, and communicate this information to employers, workers, and others.}

\section{TARGET ACTION}

Employers, policymakers, standard-setting organizations, and others use NIOSH research and communication materials on motor vehicle crash and injury risk factors to develop or improve policies, programs, safety interventions, safety standards and regulations, and guidance documents.

\subsection{OIL AND GAS EXTRACTION}

Tactic 1.1.1 Identify barriers to seat belt use and factors that influence workers' decision making and adoption of this safety behavior.

Tactic 1.1.2 Identify and characterize fatigue-

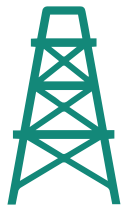
related risk factors that lead to a better understanding of the extent to which work organization factors (e.g., work hours and schedules) and individual factors (e.g., commuting times and distance) influence motor vehicle safety, and crash and injury occurrence.

Tactic 1.1.3 Identify and characterize sources of driver distraction for oil and gas extraction workers (e.g., electronic devices) to inform effective prevention strategies.

Tactic 1.1.4 Identify best practices to communicate and disseminate information to oil and gas employers and workers on safety and health factors linked to motor vehicle crash and injury risks.

\subsection{PUBLIC SAFETY}

No related priorities in the NIOSH Strategic Plan: FYs 2019-2023 for these types of basic/etiologic research

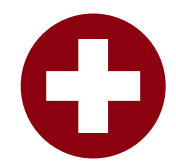

\subsection{TRANSPORTATION, WAREHOUSING, AND UTILITIES}

Tactic 1.3.1 Identify and characterize the influence of work organization factors (e.g., carrier policies and practices,

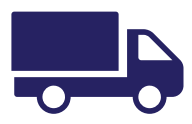
compensation practices, scheduling, work hours, uncompensated and unlogged time) for commercial motor vehicle (CMV) drivers on work-related crashes and crash-related injuries.

Tactic 1.3.2 Increase knowledge of how individual driver and road user factors (e.g., age; years of experience; training; driving practices; health status and behaviors; sleep habits; prescription drugs [including opioids], illicit drugs, and substances; and road user type [e.g., pedestrian, motorcyclist, bicyclist]) impact work-related crashes and crash-related injury.

Tactic 1.3.3 Describe the interaction of driver fatigue and distracted driving and its impact on driving performance.

Tactic 1.3.4 Identify best practices to communicate and disseminate information to drivers and carriers on safety and health factors associated with crash and injury risks. 


\section{STRATEGY 1}

Tactic 1.3.5 Obtain baseline measurements of fatal and non-fatal crash and injury occurrence among gig workers, whose jobs are linked to a digital online platform (e.g., ride sourcing services, e-bike messengers).

Tactic 1.3.6 Evaluate potential metrics beyond traditional rates per million vehicle miles traveled to measure safety performance to account for industry-wide changes in trip lengths and routes.

\subsection{WHOLESALE AND RETAIL TRADE}

No related priorities in the NIOSH Strategic Plan: FYs 2019-2023 for these types of basic/etiologic research.

\subsection{ALL SECTORS}

Tactic 1.5.1 Evaluate new sources of data for measuring worker exposure to the risk of motor vehicle crashes and crash-related injury.

Tactic 1.5.2 Assess the use and impact of prescription and over-the-counter medications on risk of work-related crashes and crash-related injury among workers who drive on the job.

Tactic 1.5.3 Identify differences in safety-related decision making when driving on and off the job. Explore rationale for any differences. 


\section{Develop and evaluate the effectiveness of engineering and technology-based interventions to prevent work-related motor vehicle crashes and injuries, and advance adoption of these interventions.}

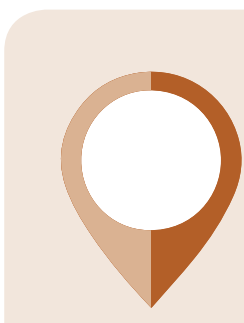

\section{TARGET ACTION}

Employers, manufacturers, standard setting organizations, policymakers, and others use $\mathrm{NIOSH}$ research results and communication materials to implement effective engineering and technology-based interventions, safety standards, and regulations for crash and injury prevention.

\subsection{OIL AND GAS EXTRACTION}

Tactic 2.1.1 Assess employee drivers' understanding and use of advanced driver assistance systems (ADAS) ${ }^{2}$ and automated driving systems $(A D S)^{3}$ in fleet vehicles.

Tactic 2.1.2 Develop and evaluate strategies to improve employee drivers' understanding of ADAS and ADS in fleet vehicles.

Tactic 2.1.3 Evaluate the effectiveness of in-vehicle technologies that detect, warn, and intervene to prevent fatigue-related crashes, including employee drivers' acceptance of and response to these technologies.

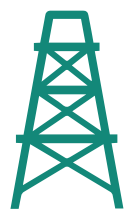

\subsection{PUBLIC SAFETY}

Tactic 2.2.1 Identify and characterize distraction or attentional overload associated with aftermarket devices installed in law enforcement and emergency response vehicles.

Tactic 2.2.2 Develop engineering and administrative control measures to mitigate risks of distraction or attentional overload associated with aftermarket devices installed in law enforcement and emergency response vehicles.

Tactic 2.2.3 Develop and evaluate interventions to improve law enforcement officers' situational awareness while handling traffic incidents, including those where the officer is inside or outside the vehicle.

Tactic 2.2.4 Identify and evaluate the safety benefits of technologies (including vehicle-to-vehicle $[\mathrm{V} 2 \mathrm{~V}]^{4}$ and vehicle-to-infrastructure $[\mathrm{V} 2 \mathrm{I}]^{5}$ ) in law enforcement and emergency response vehicles.

\footnotetext{
${ }^{2}$ Safety technology in vehicles operating at SAE automation levels 0-2, assisting the driver by steering and/or braking/accelerating. ADAS may warn the driver of a traffic hazard, brake to avoid a collision, or correct and maintain lane position. Adapted from: ANSI/ASSP [2019]. ASSP Technical Report: Management practices for the safe operation of partially and fully automated vehicles (ASSP TR-Z15.3 - 2019).

${ }^{3}$ The hardware and software which together are able to perform the driving task on a sustained basis under certain conditions or for an entire trip, without requiring the human driver to monitor the driving environment. An ADS operates at SAE automation levels 3-5. Adapted from: SAE [2016]. Surface Vehicle Recommended Practice J3016: Taxonomy and definitions for terms related to driving automation systems for on-road motor vehicles.

${ }^{4}$ Vehicle-to-vehicle (V2V) communication is the wireless exchange of speed, positional, and other data between motor vehicles.

${ }^{5}$ Vehicle-to-infrastructure (V2I) communication is the wireless exchange of data between vehicles and road infrastructure components such as lane markings, road signs, and traffic signals.
} 


\subsection{TRANSPORTATION, WAREHOUSING, AND UTILITIES}

Tactic 2.3.1 Assess the impact of automation (including V2 V and V2I technologies) on worker situational

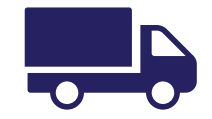
awareness and engagement while driving a truck, bus, or taxi.

Tactic 2.3.2 Assess employee drivers' comprehension and use of advanced driver assistance systems (ADAS) and automated driving systems (ADS) in commercial motor vehicles.

Tactic 2.3.3 Develop and evaluate strategies to improve employee drivers' understanding of the capabilities of ADAS and ADS in commercial motor vehicles.

Tactic 2.3.4 Evaluate the effectiveness of in-vehicle technologies to detect, warn, and intervene to prevent fatigue-related crashes and crash-related injury among drivers of large trucks. ${ }^{6}$

Tactic 2.3.5 Evaluate technology-based interventions to reduce crash and crash-related injury risks due to fatigue or distraction among drivers for hire.

\subsection{WHOLESALE AND RETAIL TRADE}

Tactic 2.4.1 Develop and evaluate strategies to improve employee drivers' understanding of and adaptation to advanced driver assistance systems

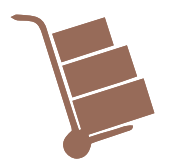
(ADAS) and automated driving systems (ADS) in fleet vehicles.

Tactic 2.4.2 Evaluate the effectiveness of in-vehicle technologies to detect, warn, and intervene to prevent fatigue-related crashes and crash-related injury among drivers of large trucks.?

\subsection{ALL SECTORS}

Tactic 2.5.1 Evaluate the effectiveness of humansystems integration designs of specialized work vehicles to prevent distraction, misjudgment, or fatiguerelated crashes and injuries, including employee drivers' acceptance, response, and adaptation to these technologies.

Tactic 2.5.2 Compare different types of fatigue detection and warning technologies, considering factors such as sensitivity, reliability, ability to detect fatigue before its symptoms appear, and user acceptability. ${ }^{8}$

\footnotetext{
${ }^{6}$ This includes assessing the extent to which these technologies will motivate drivers to stop the vehicle and take a break.

${ }^{7}$ This includes assessing the extent to which these technologies will motivate drivers to stop the vehicle and take a break.

${ }^{8}$ These technologies may be manufacturer-installed, aftermarket installations, wearables, or app-based.
} 


\section{Evaluate the effectiveness of motor vehicle safety management programs and practices and promote their adoption.}

\section{TARGET ACTION}

Employers, industry associations, standard setting organizations, policymakers, and others use $\mathrm{NIOSH}$ research results and communication materials to develop and apply effective motor vehicle safety management standards, regulations, programs, and practices.

\subsection{OIL AND GAS EXTRACTION}

Tactic 3.1.1 Evaluate strategies to increase the use of seat belts among oil and gas contract workers. ${ }^{9}$

Tactic 3.1.2 Evaluate the use of fatigue risk

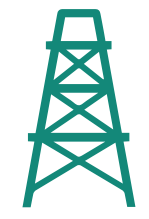
management systems (FRMS) and other strategies, including fatigue detection technologies, to reduce fatigue and fatigue-related crashes and injuries among employees of small businesses and well servicing companies.

Tactic 3.1.3 Evaluate tools to help employers align practices in the field with corporate policies (e.g., stop work authority), to ensure effective and sustainable administration of interventions and enhance safety culture.

Tactic 3.1.4 Identify ways to reduce barriers (e.g., cost, time) to the adoption of effective motor vehicle safety interventions, such as in-vehicle monitoring systems (IVMS), among employers and workers in small businesses and well servicing companies.
Tactic 3.1.5 Evaluate employers' and workers' acceptance of cell blocking technologies to reduce phone-related distracted driving and distracted driving crashes and injuries among oil and gas workers.

Tactic 3.1.6 Evaluate the impact of varying driver compensation systems and dispatching practices on risky driving behaviors (e.g., speeding), crashes, and injuries for trucks used in the oil and gas industry. ${ }^{10}$

\subsection{PUBLIC SAFETY}

Tactic 3.2.1 Evaluate the safety consequences and cost-benefit of public safety agencies' operational policies on

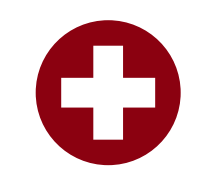
crashes and injuries to firefighters, law enforcement officers, and emergency medical services (EMS) workers who are vehicle occupants or pedestrians."

Tactic 3.2.2 Identify incentives and barriers to adoption of motor vehicle safety policies in public safety agencies, comparing fire, law enforcement, and EMS agencies.

Tactic 3.2.3 Evaluate the effectiveness of intra-shift fatigue management strategies such as napping and rest breaks on fatigue and crash-related injury risk for EMS workers. This includes examining the traditional EMS employee 24-hour shift schedule.

\footnotetext{
${ }^{9}$ Consider incorporating storytelling and neuroscience research on habit change.

10 Many truck drivers in the industry are paid by the load while others are paid by the hour. Some insurance companies decline to insure those who pay by the load. The extent to which these different systems are used is unknown, as are the impacts of varying systems of payment.

1 This might include increasing the number of fire apparatus deployed to fire and incident scenes, or policies that call for firefighters to travel to the scene out of gear.
} 


\section{STRATEGY 3}

Tactic 3.2.4 Develop and evaluate policies associated with installment and use of in-cab communication and information systems in law enforcement vehicles (e.g., mobile data terminals) to minimize potential for distraction and attentional overload.

Tactic 3.2.5 Evaluate fatigue risk management systems (FRMS) and other strategies for law enforcement officers.

Tactic 3.2.6 Evaluate traffic incident management training, policies, and standard operating procedures used in the towing and recovery industries that might affect crash-related injury risk for public safety workers during roadside or other emergency responses.

\subsection{TRANSPORTATION, WAREHOUSING, AND UTILITIES}

Tactic 3.3.1 Develop and evaluate fatigue risk management systems (FRMS) and other strategies for employers to address fatigue and sleep

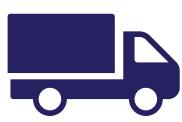
disorders and associated crash and crash-related injury risks among truck drivers employed by small carriers (i.e., 10 or fewer trucks). Consider cost effectiveness in evaluation.

Tactic 3.3.2 Evaluate the impact of worker health and wellness programs (e.g., obesity prevention, physical activity, sleep health) on crash and crash-related injury risk among truck drivers.

Tactic 3.3.3 Evaluate the effectiveness and cost-benefit of fleet safety and operational strategies (e.g., shift scheduling, time of day, route planning, truckload vs less-than-truckload) to reduce crash and crash-related injury risk for truck drivers.
Tactic 3.3.4 Develop and evaluate evidence-based motor vehicle safety toolkits and other interventions to reach drivers for hire (e.g., taxi drivers, gig workers whose jobs are linked to a digital online platform), addressing key issues such as fatigue, distraction, and compliance with traffic laws (e.g., seat belt use). ${ }^{12}$

Tactic 3.3.5 Evaluate interventions to reduce the impacts of the use and misuse of prescription drugs (including opioids), illicit drugs, and substances on motor vehicle crashes and related injuries among truckers, taxi drivers, and gig workers whose jobs are linked to a digital online platform.

\subsection{WHOLESALE AND RETAIL TRADE}

Tactic 3.4.1 Develop and evaluate initiatives to reduce crash and crash-related injury risk among gig workers who deliver packages and groceries, whose jobs are linked to a digital online platform. ${ }^{13}$

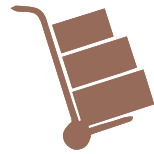

Tactic 3.4.2 Conduct translational research to determine the most effective ways to reach small employers in the wholesale sector with motor vehicle safety information, partnering with workers' compensation and auto insurance carriers.

Tactic 3.4.3 Demonstrate the business case for motor vehicle safety programs within the wholesale and retail trade sector.

\footnotetext{
${ }^{12}$ Reaching this population will require partnerships with key intermediaries that can facilitate cross-cultural communication.

${ }^{13}$ Research in this area should consider seasonal and weather factors that increase demand for driving by this workforce.
} 


\section{STRATEGY 3}

\section{ALL SECTORS}

Tactic 3.5.1 Develop and evaluate safety culture initiatives to help employers to gain worker and front-line management buy-in and compliance with motor vehicle safety programs and policies.

Tactic 3.5.2 Develop and evaluate interventions that increase the skills of front-line management to improve driver behavior.

Tactic 3.5.3 Identify and communicate best practices for the integration of fatigue risk management systems (FRMS) into motor vehicle safety programs and occupational safety and health management systems.

Tactic 3.5.4 Evaluate the implementation of FRMS and their impact on drivers' risk-based decisions (e.g., whether or not to rest before driving) prior to driving on the job.

Tactic 3.5.5 Evaluate methods to mitigate the effects of cognitive distraction for drivers, including the roles of organizational and supervisor communication of relevant safety policies. 


\section{COMMUNICATION STRATEGIES}

Research leads to new knowledge, while communication makes that knowledge accessible, applicable, and meaningful to a wider audience. The CMVS will use bestpractice communication principles and research results to assist $\mathrm{NIOSH}$ and $\mathrm{NIOSH}$-funded researchers with translating motor vehicle safety research into practice.

RTI International conducted an audience analysis in 2017 on behalf of the CMVS to find out

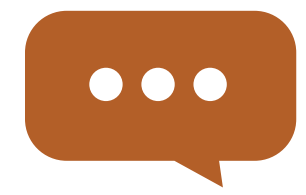
what motor vehicle safety topics and products would be most useful to small businesses, which often lack the resources to develop their own safety materials. The study included focus groups of managers whose employees and contractors frequently drive for work, representing the four industry sectors emphasized in this CMVS strategic plan. Key findings that apply across sectors are that information should be tailored, brief, simple, and visually engaging to capture an audience's attention. Information that is mobile-friendly or viewed quickly in print format is also desirable.

Insights from NIOSH subject matter experts who have interacted with industry sectors also help CMVS communicators understand an audience's unique communication preferences. The CMVS will continue to foster discussions among subject matter experts, communication specialists, industry representatives, and worker representatives to get the right message to the right audience in a meaningful way. This is where strategies that tailor content to meet industryspecific needs come into play. For example, what works for the Public Safety sector might not work for the Oil and Gas Extraction sector, and what works for employers might not work for workers.

These communication strategies integrate lessons learned from the audience analysis by RTI International, consultation with subject matter experts, and best-practice communication principles: ${ }^{14}$

- Identify the audience. Employers, workers, researchers, and the general public have different needs.

- Learn what is important to the audience. Appeal to what motivates the identified audience to learn, think, or do.

- Keep messages short and simple. Focus on a few key messages and use plain language, unless a term is commonly known, understood, and used by your audience. For example, "mobile data terminal" (or MDT) can be used in messages for the law enforcement community because it is widely understood.

- Enhance the message with visuals. Add icons, high-quality photos, or other graphics that reinforce the text.

- Design with the reader in mind. Organize content into short chunks of text, bulleted lists, or other easy-to-read formats.

- End with a call to action. Provide readers with a concrete action step.

In addition to applying the strategies mentioned above, the CMVS will continue to use multiple communication channels and formats and will explore emerging communication practices.

${ }^{14}$ The CMVS refers to guidelines from the CDC Clear Communication Index, plainlanguage.gov, and the Center for Plain Language. 


\section{ACHIEVING IMPACT AND EVALUATING THE PLAN}

The evaluation of this CMVS strategic plan will assess its implementation as intended and its influence on work-related motor vehicle safety research and communication activities supported by $\mathrm{NIOSH}$. The evaluation will also describe the impact of $\mathrm{NIOSH}$ safety research and communication on improving motor vehicle safety in the workplace.

In evaluating the implementation of this strategic plan, the CMVS Lead Team will consider a tactic to have been addressed if there is a corresponding project or product from internal NIOSH researchers or external NIOSH-funded researchers. The CMVS Lead Team will track initiation and progress of research projects; production of publications and related products; and development, evaluation, and adoption of safety interventions and management practices. Projects and products developed during the period covered by the strategic plan will be reported by industry and strategy.

We do not expect that all tactics in this plan will be addressed during the 10-year period. The plan contains a relatively long list of tactics, giving NIOSH-funded researchers the opportunity to choose based on their areas of expertise and interest. Therefore, influence of the strategic plan on NIOSH research and communications will be measured by the plan's correspondence with NIOSH and NIOSH-funded projects, products, and interventions, rather than implementation of a specific number of tactics. Since the CMVS strategic plan is intended to give the greater research community insight into NIOSH CMVS priorities, the hope is to stimulate project ideas that are pursued and funded by organizations outside of NIOSH. The CMVS Lead Team has a limited ability to evaluate this effect because there is currently no systematic, cost-effective way to identify decisions made by external organizations based on the CMVS strategic plan.

The CMVS will also assess the impact of NIOSH safety research and communication on improving motor vehicle safety in the workplace. To describe impact, the CMVS will develop a series of "impact stories" for selected industries and worker groups. These stories will demonstrate progress from identifying research needs; conducting research; developing scientific, technical, and educational products; and communicating key findings to drive motor vehicle safety improvements in the workplace. 


\section{APPENDIX}

\section{ROLE OF THE NIOSH STRATEGIC PLAN: FYs 2019-2023}

The NIOSH Strategic Plan: FYs 2019-2023 defined the scope of the CMVS strategic plan for 2020-2029 in several ways.

Industry sectors: In the NIOSH strategic plan, four industry sectors prioritized motor vehicle safety research: Oil and Gas

Extraction; Public Safety; Transportation, Warehousing, and Utilities; and Wholesale and Retail Trade.

Within each industry sector, priorities are further defined according to:

- Safety issues: Factors that increase the risk of a crash or injury. Some factors are related to driver behavior, such as not using a seat belt or distracted driving. Others are related to work organization, such as method of paying drivers, working hours, safety regulations, and employer road safety policies.

- Worker populations: Those with the greatest burden of crashes or injuries, and whom research could benefit the most.

- Types of research needed:

- Basic/etiologic: Builds a scientific knowledge base for interventions by identifying injury risk factors. This might be done through data analysis or laboratory or field research.

- Intervention: Develops, tests, or evaluates solutions to a workplace safety problem. Motor vehicle safety interventions include engineering controls, administrative changes, safety technologies, and educational campaigns.

- Translation: Discovers strategies to transform research findings into tools that can be applied and accepted in the workplace. This type of research might also explore why interventions known to be effective are not adopted.

- Surveillance: Develops new methods and tools to collect and analyze injury data.

\section{THE NIOSH STRATEGIC PLAN: FYs 2019-2023: INTERMEDIATE GOALS FOR MOTOR VEHICLE SAFETY}

Below are intermediate goals for the industry sectors that have prioritized motor vehicle safety, as they appear in the NIOSH Strategic Plan: FYs 2019-2023. Achieving an intermediate goal means that NIOSH research results and communication activities have led to the transfer of information to key intermediaries who are positioned to take actions that will improve motor vehicle safety at work.

- Oil and Gas Extraction: Professional associations, insurers, employers, workers, and other government agencies use $\mathrm{NIOSH}$ information to prevent motor vehicle crashes among oil and gas extraction workers.

- Public Safety: Public safety department management, labor organizations, workers, and consensus standard organizations adopt interventions based on $\mathrm{NIOSH}$ research to prevent motor vehicle incidents and resulting injuries among public safety workers.

- Transportation, Warehousing, and Utilities: Employers, insurers (including workers' compensation), standard setting bodies, other government agencies, manufacturers, professional associations, and labor organizations use NIOSH information to reduce transportation incidents and related injuries among transportation, warehousing, and utilities workers.

- Wholesale and Retail Trade: Employers, insurers, and workers in the wholesale and retail trades adopt effective interventions to prevent injuries due to motor vehicle crashes. 